\title{
The Phenomenon of Anomalous Rock Embrittlement
}

\author{
B.G. Tarasov, A.V. Dyskin School of Civil and Resource Engineering, The University of Western Australia
}

The paper analyses a phenomenon of rock behaviour - the embrittlement under the effect of confining pressure and dynamic impact. The increase in confining pressure and strain rate generally makes the post-peak behaviour of rocks more ductile. Some rocks however are capable of increasing their post-peak stiffness at a certain (critical) range of confining pressures or strain rates. There are reasons to believe that the cause of embrittlement in both cases is the same: the specific change in the failure mechanism. Within the critical range the failure localises along a single plane, subsequently the failure process is characterised by relatively low energy consumption resulting in a stiff post-peak branch. Outside the critical range the failure pattern is more dispersed, the process is more power-consuming, which softens the post-peak branch. The paper introduces a possible mechanism of rock embrittlement and discusses the effect of this phenomenon on the loss of stability in rockmass surrounding an underground excavation. It is shown that this phenomenon can cause such types of instability as burst fracture and rockburst of remote origin.

\section{INTRODUCTION}

The paper presents results of an investigation of an abnormal rock behaviour associated with embrittlement induced either by increase in confining pressure or dynamic loading. This phenomenon was reported earlier (Santarelli and Brown, 1989; Stavrogin and Tarasov, 2001). Increase in confining pressure and strain rate generally makes the post-peak behaviour of rocks more ductile. Some rocks however are capable of increasing their post-peak stiffness at a certain (critical) range of confining pressures or strain rates.

It is reasonable to suppose that the abnormal rock embrittlement observed in laboratories can also manifest itself in rockmass conditions (Santarelli and Brown, 1989; Stavrogin and Tarasov, 2001). For instance, in certain cases this phenomenon can initiate the loss of the excavation stability in areas where rocks with the normal behaviour are regarded as stable. Therefore, ignoring this phenomenon could lead to a considerable underestimation of the risk of rock failure.

Despite the experimental discovery of the phenomenon it is still not clear what features of rock microstructure provide such material behaviour and what the mechanism of the failure localization is. The paper aims at discussing possible mechanisms of the embrittlement and presents some recent experimental results. These results are obtained using a stiff triaxial static dynamic testing machine (see description in Appendix).

\section{ROCK EMBRITTLEMENT BY CONFINING PRESSURE AND THE OPENING STABILITY}

The dolerite that has been tested belongs to the type of rock with abnormal behaviour. The results shown in Figures 1 and 2 illustrate this.

At confining pressures $\sigma_{3}=0$ (uniaxial compression) and $10 \mathrm{MPa}$ the failure process is characterised by the development of many cracks some of which are oriented along the specimen axes and some are inclined (see the photograph in Figure 1). The formation of such a system of cracks requires relatively large amount of energy. Graphically the total energy absorbed by the cracks is represented by the total area under the stressstrain curve. An important point is that the total absorbed energy here is the sum of the energy accumulated within the specimen at the peak strength and the energy additionally supplied by the loading system in the post-peak region. In this case the post-peak modulus $M$ of the material is negative and the failure process is controllable by a sufficiently stiff loading machine.

At confining pressures $\sigma_{3}=30$ and $50 \mathrm{MPa}$ the failure mechanism is different. Here the failure localises along a single shear plane. The total energy consumption associated with the formation of this plane is smaller than the amount of elastic energy accumulated within the specimen at the peak strength. Graphically this energy is represented by the area located between pre-peak and post-peak parts of the stress-strain curve. The post-peak part of the curve in this case is characterized by the positive value of modulus $M$. In the present tests we managed to obtain only the initial parts of the post-peak curves despite the very high stiffness and modern servo-control of the loading machine. The further failure process was uncontrollable and violent. The released energy in this case is emitted by both the specimen and the loading system.

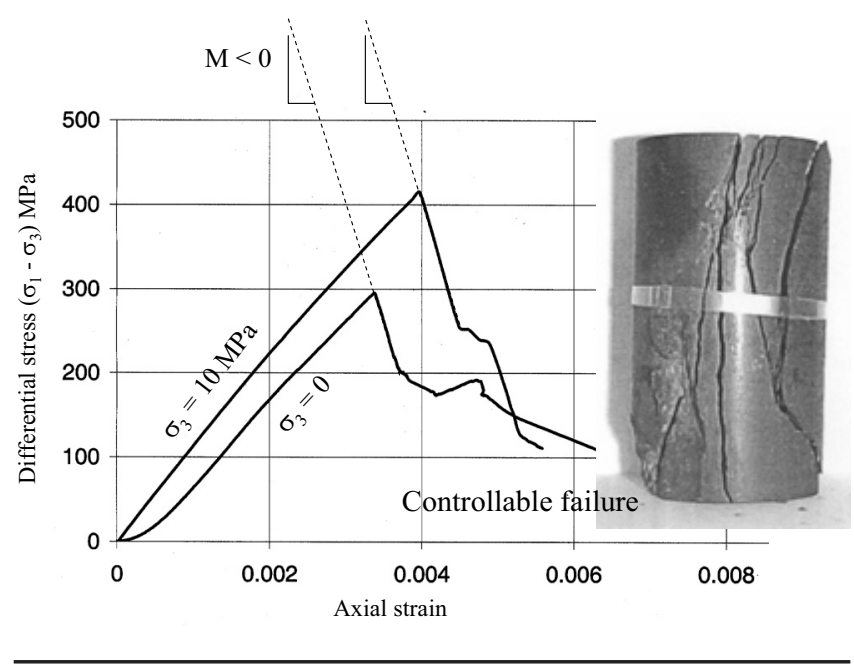

FIG. 1 Stress-strain curves and failure pattern of dolerite at $\sigma^{3}=0$ and $10 \mathrm{MPa}$ 


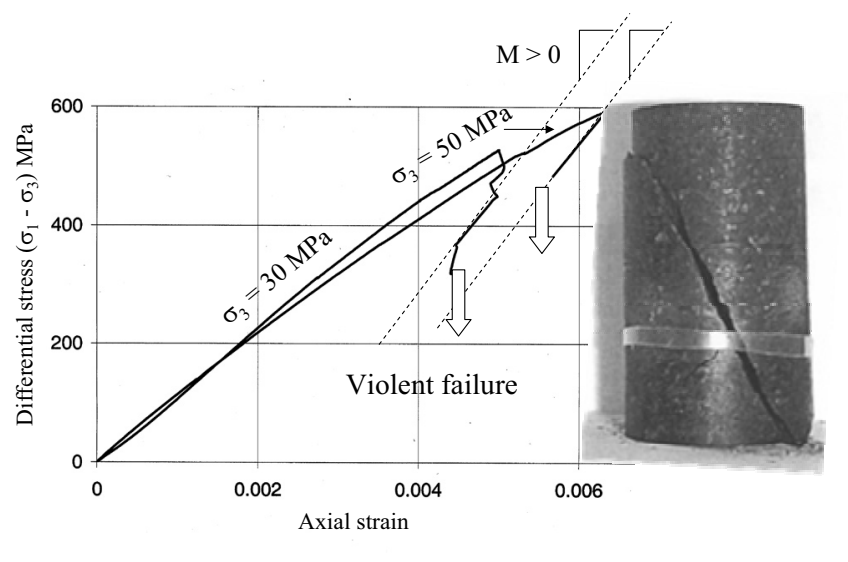

FIG. 2 Stress-strain curves and failure pattern of dolerite at $\sigma^{3}=30$ and $50 \mathrm{MPa}$

Figure 3 schematically illustrates the difference in the energy redistribution in the tests discussed above. Diagrams $\mathrm{ABC}$ in Figure 3(a) and (b) represent stress-strain curves for the material tested at low and high confining pressures correspondingly. (These diagrams do not take into account the variation in peak strength and residual strength at different confining pressures. They show only the difference in the energy release caused by the change in sign of the postpeak modulus $M$.)

a)

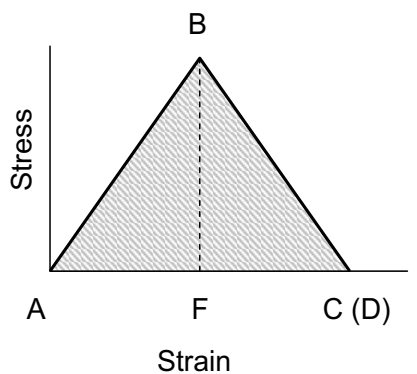

b)

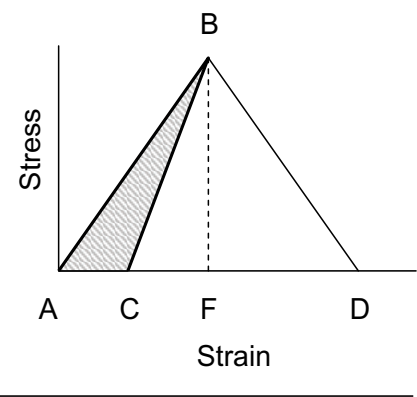

FIG. 3 Schematic illustration of the energy release in the tests discussed above

Assume that at low confining pressure the characteristics of stiffness for the material in the post-peak region (BC) and for the loading system (BD) are equal. In this case the failure process in the post-peak region should be stable. All elastic energy accumulated at the peak strength both within the material (energy $W_{m}$ represented by area $\mathrm{ABF}$ ) and within the loading system (energy $W_{1}$ represented by area FBD) will be absorbed by the crack formation process. The absorbed energy $W_{a b}$ is represented by shaded area ABC. Hence, the released energy that can be transformed in dynamic forms of energy, $W_{d}$, in this case can be assumed to vanish.

$$
W_{d}=W_{s}+W_{1}-W_{a b}=0
$$

At high confining pressures the situation is completely different. Here the failure process absorbs only a portion of elastic energy stored within the material. The absorbed energy $W_{a b}$ corresponds to shaded area ABC. Elastic energy of the loading system transforms entirely into the dynamic forms of energy. The white area, CBD, represents the released energy emitted from the material and the loading system. This energy determines the violence of the failure process.

$$
W_{d}=W_{s}+W_{1}-W_{a b}=\text { area } \mathrm{CBD}
$$

For rock under consideration the abnormal embrittlement was observed within the range of confining pressure $30 \mathrm{MPa}$ $\leq \sigma_{3} \leq 100 \mathrm{MPa}$. Outside of this range the rock behaviour is conventional. The range of confining pressures (or minor stresses) where the rock embrittlement takes place will be called here a critical pressure range. Experiments show that for different rocks the critical pressure range can be very different.

The rock embrittlement induced by confining pressure discussed above poses a number of questions:

i Which features of the rock microstructure are responsible for the embrittlement?

ii What is the mechanism of failure localization?

iii Can the embrittlement take place in rockmass or it is a feature of rock behaviour in the laboratory conditions?

These questions can only be answered after comprehensive investigation of rocks collected from different mining areas qualified as both hazardous and nonhazardous with respect to rockburst. Before that we can only discuss the role of the rock embrittlement in the rockmass behaviour and in the stability of underground openings. However if we accept the hypothesis that the embrittlement is an intrinsic feature of some types of rock and that it can be observed in a range of scales (from specimen to rockmass) we can analyse the rockmass stability taking into account this important feature and propose some additional explanation to specific types of rockmass behaviour. The following example illustrates this possibility.

Ortlepp (1997) describes in detail the shear rupture mechanism observed in deep mines. Many photographs presented in the book and concomitant analysis proof that the source mechanism of a major form of rockburst is the shear fracture. Ortlepp writes: "The repetitive and cyclic nature of these fractures argues strongly for a process whereby mining-induced stress increases in a zone ahead of, and below, the longwall face to a critical level at which failure occurs violently. This failure drives a new rapture along a more-or-less plane surface whose attitude and extent is determined by the prevailing stress field." During this failure process "a very large amount of energy is suddenly and violently emitted from somewhere in the semi-infinite rock-space surrounding a mine, to express itself as a large rockburst."

In his analysis Ortlepp notes that the burst ruptures being typical for some deep mines are seldom or never encountered in others. He explains this fact by features of mining circumstances and geological nature of the rockmass surrounding the mining area. However, taking into account the existence of two types of rock, the first type exhibiting the normal behaviour and the second type exhibiting the abnormal embrittlement, we can look at this fact from another point of view.

Figure 4 schematically illustrates a situation around an opening located in rockmass exhibiting the embrittlement within a certain critical range of the values of minor stress $\sigma_{3}$. A qualitative diagram 'stress $\sigma_{3}$ vs. distance from the opening $d$ ' shown in the picture indicates the critical pressure range within which the material acquires high brittleness. A shaded zone (zone 2) surrounding the opening where the value of $\sigma_{3}$ is critical represents rockmass being in the state of abnormal behaviour. This zone is located between zone 1 and zone 3 where rock is in the normal state.

If the mining-induced stress $\sigma_{1}$ reaches the rock strength level within zone 2 a shear rupture will spontaneously erupt here and than propagate towards zones 1 and 3 . 


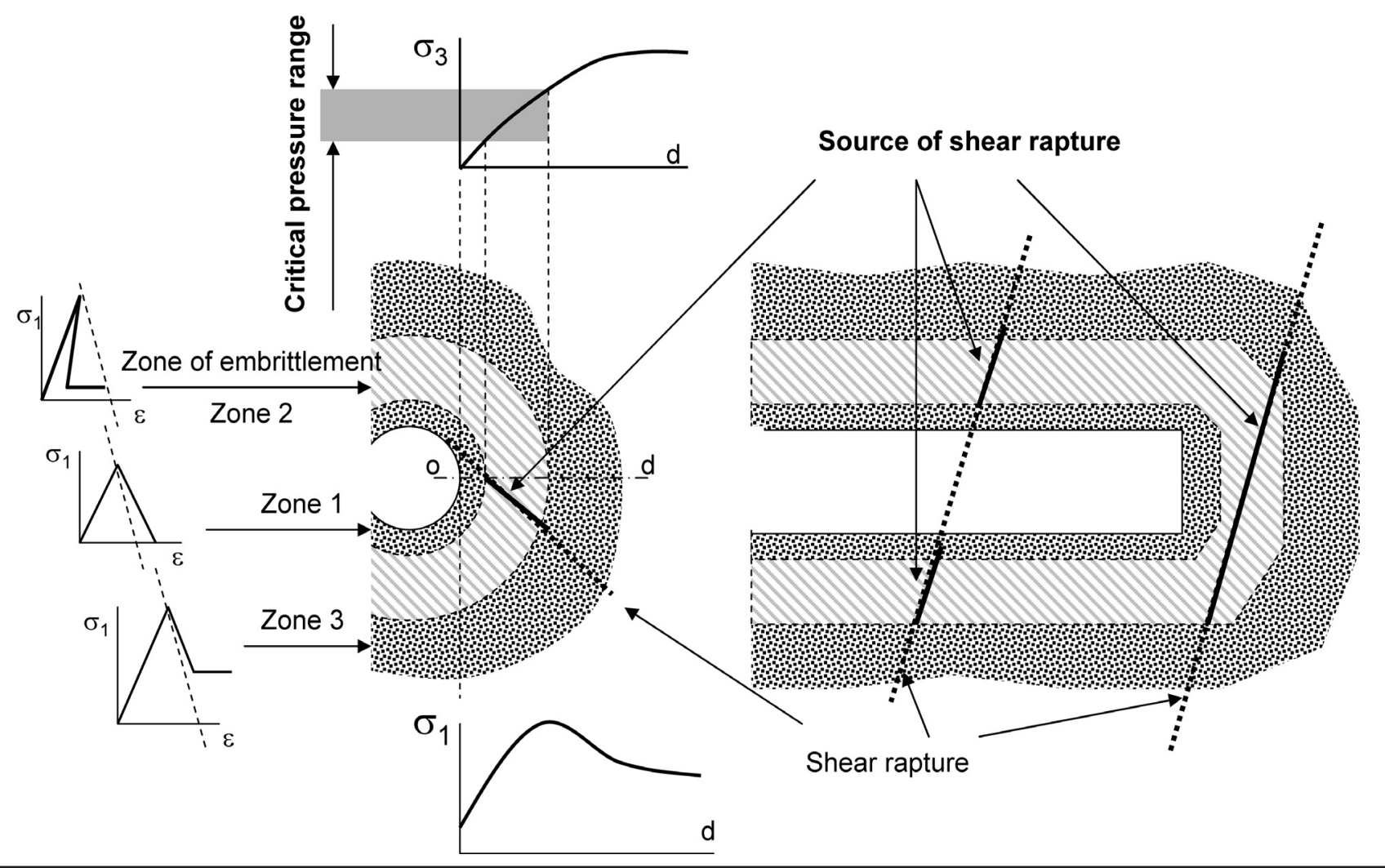

FIG. 4 Illustration of a situation around an opening located in rockmass with the abnormal behaviour

The shear rupture direction and its extent are determined by the prevailing stress field. Three of many possibilities of the shear rupture location are shown in the picture.

The development of the fracture is accompanied by a relaxation of the stress concentration in this area. The very large amount of elastic energy that can be released in such events is caused by two factors: i) high rock brittleness within zone 2 and ii) position of the maximum concentration of stress $\sigma_{1}$ in the same zone 2. The released energy transforms in such forms of dynamic energy as dynamic movement of rockmass, seismic oscillation and, in some cases, in kinetic energy of flying rock fragments.

The phenomenon of embrittlement in rockmass can only take place below a certain critical depth. Figure 5 explains this statement. A vertical opening here is shown by dotted lines. Graphs 'minor stress $\sigma_{3}$ vs. distance from the opening $d^{\prime}$ illustrate the stress situation near the opening at different depths. Shaded areas on these graphs represent the critical stress range within which the rock becomes abnormally brittle. At depths where the minor stresses $\sigma_{3}$ reach values corresponding to the critical stress range the effect of embrittlement can take place if the major stresses $\sigma_{1}$ initiate the failure process.

Hence, we can conclude that according to the discussed mechanism shear rupture can be initiated in rockmass surrounding an opening if three conditions are satisfied: i) the rock exhibits embrittlement at confined conditions; ii) the minor stresses are within the critical stress range; iii) the major stress in the zone of rock embrittlement reaches the rock strength. In deep mines where these conditions are not satisfied completely the occurrence of rockburst associated with the shear rupture is unlikely.

\section{ROCK EMBRITTLEMENT IN DYNAMIC LOADING}

Usually the increase in strain rate increases the rock strength and ductility both in pre and post-peak regions. Such change in rock properties is similar to that generally induced by confining pressure. However some rocks exhibit abnormal behaviour in dynamic loading associated with the decrease in strength or embrittlement in the post-peak region.

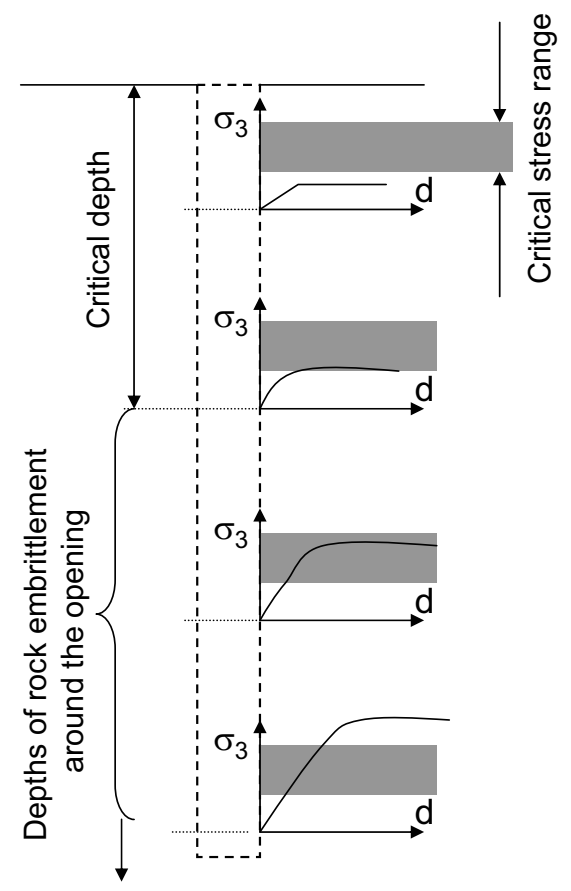

FIG. 5 Graphical estimation of the critical depth below which the abnormal rock embrittlement can take place

An important point is that the same rock can show both normal and abnormal behaviour depending on the loading conditions. Results obtained on rock salt (Figure 6) and sandstone (Figure 7) illustrate this feature, Stavrogin and Tarasov (2001). In these figures the vertical axis corresponds to the shear strength $\tau^{\varsigma}=\left(\sigma_{1}-\sigma_{3}\right) / 2$; the horizontal axis 
corresponds to the $\log$ arithm of strain rate $\log \varepsilon^{*}$. Data points on each graph represent rock strength at different levels of strain rate.

Rock salt was tested in uniaxial compression within the total range of strain rates $10^{-8}-10^{2} \mathrm{~s}^{-1}$. Within the range $10^{-8}-10^{-6} \mathrm{~s}^{-1}$ the material behaviour is usual. The increase in strain rate here causes the increase in strength. At greater strain rates we can observe significant degradation of the rock strength with increasing of $\varepsilon^{*}$. The maximum strength degradation in the discussed range of strain rates is about $40 \%$.

Sandstone was tested in uniaxial compression and confined $\left(\sigma_{3}=100 \mathrm{MPa}\right)$ compression within the same total range of strain rates. This rock also exhibits both strength degradation and strengthening in different ranges of strain rate. Unlike the rock salt the sandstone decreases its strength at low strain rates and shows strengthening within the range of high strain rates. At confined conditions this effect is more significant and the strength degradation amounts $25 \%$.

Some rocks can exhibit abnormal behaviour at a certain level of confining pressure while at other confined conditions their behaviour is normal. Sometimes together with the increase in strength at dynamic loading the significant embrittlement takes place in the post-peak region. Experiments show that dynamic loading can cause the failure localization even at high confining pressures where at static conditions the material behaviour is absolutely plastic. Figure 8 illustrates this feature. Basalt specimens were tested at confining pressure $\sigma_{3}=200 \mathrm{MPa}$ in static $\left(\varepsilon^{*}{ }_{1}=10^{-5} \mathrm{~s}^{-1}\right)$ and dynamic $\left(\varepsilon^{*}{ }_{1}=8 \mathrm{~s}^{-1}\right)$ regimes

The static stress-strain curve shows that at these conditions the material behaviour after the achievement of the yield stress is plastic. The macroscopic irreversible deformation here occurs along many shear planes uniformly distributed within the specimen body. The traces of these planes are seen on the specimen surface.

Results obtained in the dynamic loading demonstrate a significant strengthening effect (about $40 \%$ ), the absence of residual strain before the peak strength and failure localization along the only plane. The material behaviour in dynamic loading has a relatively brittle character in comparison with the static loading.

Thus, rocks exhibit many types of abnormal behaviour induced by the strain rate change. The rock strength degradation and embrittlement observed in the laboratory conditions give ground to suggest the analogous behaviour of rockmass in the field. In this case the dynamic pulses from explosions or other kinds of dynamic events can provoke the loss of the opening stability that can exhibit itself as a rockburst of remote origin.

The mechanisms of the abnormal rock behaviour in dynamic loading are still not clear. However, the analogy with rock embrittlement associated with the post-peak failure localisation observed both in confined and dynamic tests suggests the similarity in failure mechanisms that take place in these two cases. On the basis of this analogy we can assume that rocks exhibiting embrittlement under the effect of confining pressure can show the same behaviour in dynamic conditions.

\section{A POSSIBLE MECHANISM OF ROCK EMBRITTLEMENT}

The mechanism of the phenomenon of embrittlement described in the previous sections is obviously related to the mechanism of post-peak softening of rocks. Shear failure observed in triaxial loading with confining pressure below brittle-ductile transition suggests that the mechanism of post-peak softening is based on crack growth (e.g., Berry,

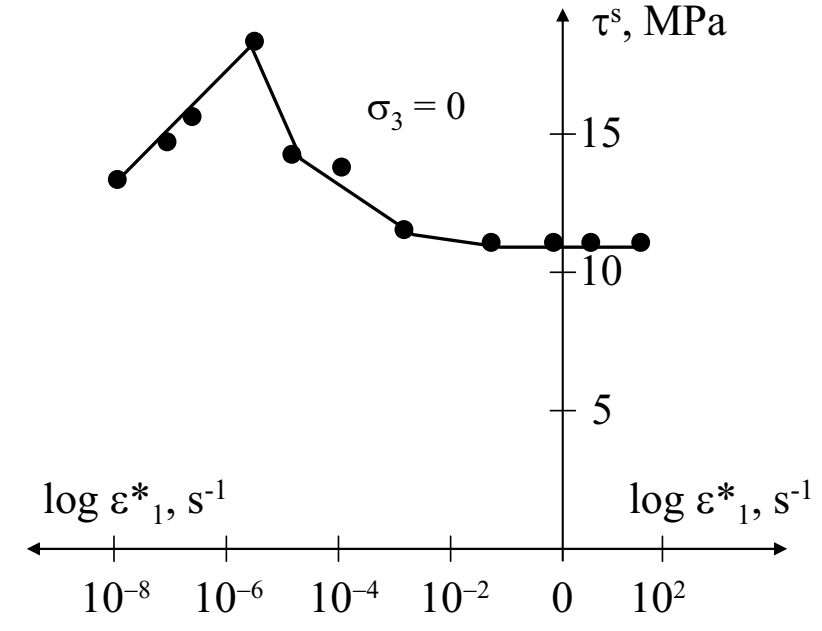

FIG. 6 Shear strength $\tau^{\text {s }}$ versus logarithm of axial strain rate $\varepsilon^{*}{ }_{1}$ for rock salt tested at $\sigma^{3}=0$

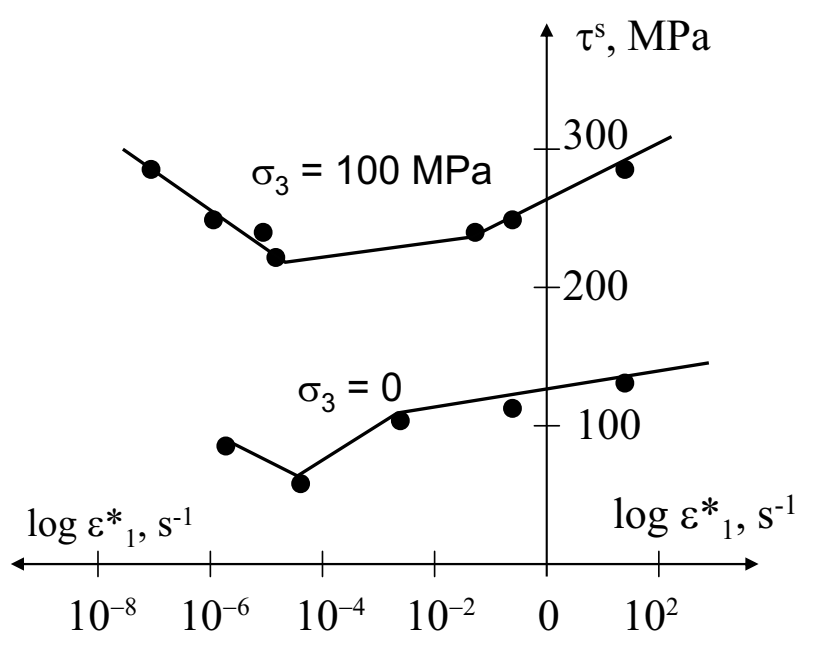

FIG. 7 Shear strength $\tau^{\text {s }}$ versus logarithm of axial strain rate $\varepsilon^{*}$ for sandstone at $\sigma^{3}=0$ and $100 \mathrm{MPa}$

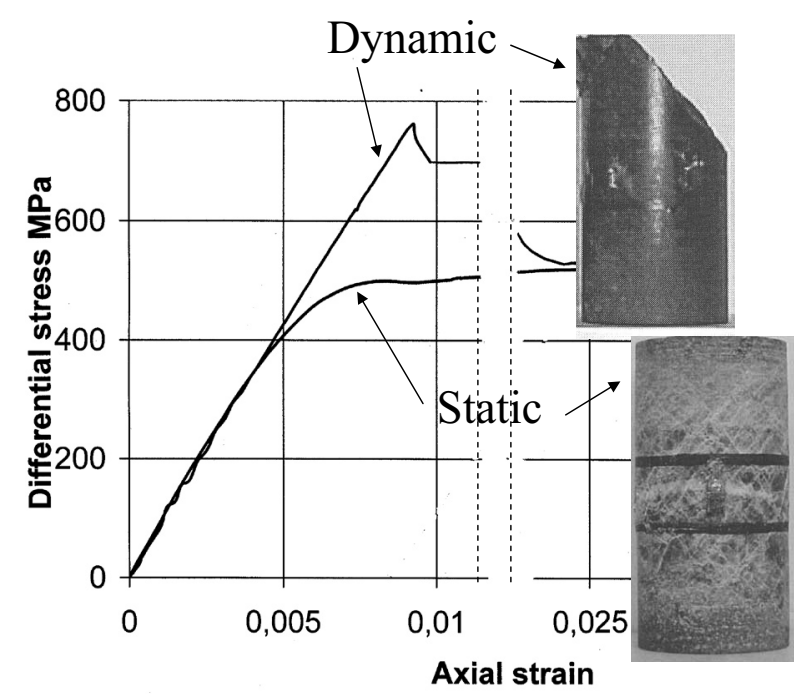

FIG. 8 Stress-strain curves and failure patterns for basalt at $\sigma^{3}=200 \mathrm{MPa}$ in static and dynamic regimes 
1960; Cook, 1965; Kemeny and Cook, 1986; Dyskin et al., 1994) which must be unstable under the peak load (otherwise the crack growth cannot be maintained in decreasing stress in the post-peak region). Three issues arise with respect to this mechanism. Firstly, while the unstable propagation of a crack under uniform loading in tension is well established and understood, the mechanism of propagation of a shear fracture still poses a challenge since, as direct experiments demonstrate, inclined cracks in compression do not propagate in their own plane, but rather kink. As a consequence, neither the formation of a shear fracture, nor their unstable growth at the critical load can be explained. Secondly, the analysis undertaken under the assumption that conditions exist that make the shear fracture propagate in its own plane, shows that if the post-peak softening is caused by the growth of a single crack, the latter must already be of a size (pre-existing or grown) comparable with the sample dimensions (Berry, 1960; Dyskin et al., 1994). The question is then what is the mechanism of formation of such a large crack prior to the peak, given that the multiple crack growth in the post-peak region is neither observed nor possible, since the first crack that starts growing brings the sample to the descending branch, the corresponding stress reduction preventing the other cracks from growth. Thirdly, what is the mechanism of embrittlement under the increase of the lateral pressure, given that the in-plane shear crack propagation in the postpeak region can be formulated in terms of effective shear stress and strain and hence qualitatively insensitive to the lateral pressure?

This section proposes a mechanism that addresses these issues. The mechanism is based on the influence of dilation in a shear crack caused by the interaction of rough surfaces, Figure 9.

Consider a crack with rough surfaces subjected to an effective shear stress

$$
\tau_{\text {eff }}=\tau-\left|\sigma_{n}\right| \tan \varphi
$$

where $\tau$ and $\sigma_{n}$ are the remote shear and normal stress acting in the crack plane, $\varphi$ is the friction angle related to the geometry of the crack surfaces, the cohesion is neglected.

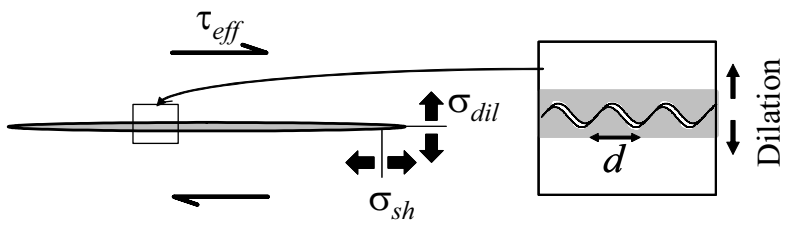

FIG. 9 Shear and dilation of a crack with rough surfaces under the effective shear stress (3): $\sigma_{s h}$ is the major principal stress associated with concentration of shear stress; $\sigma_{d i l}$ is the major principal stress associated with dilation

Shearing of such a crack causes two types of tensile stress concentration at a distance from the crack tip associated with the size of non-elastic zone (Dyskin and Galybin, 2001): $\sigma_{s h}>\sigma_{d i l}$. The conventional major principle stress $\sigma_{s h}$ would cause kinking, however further growth of the kink would be suppressed by the ambient compression. In the situation when the out-of-plane crack growth is suppressed, the only mechanism of its growth is associated with the major principle stress $\sigma_{\text {dil }}$ caused by dilating crack opening. This stress produces a straight (in-plane) crack growth. For the sake of simplicity, in order to demonstrate the main idea, we express the conditions of crack growth as follows:

$$
2 \tau_{\text {eff }} \sqrt{r / \pi}=K_{\text {IIc }}
$$

where the crack is assumed to be penny-shaped of radius $r$ and $K_{I I C}$ is an effective fracture toughness expressed in terms of shear stress concentration.

The post-peak region produced by such a crack is expressed through the Griffith locus, Figure 10 which comprises the points at which condition (4) is satisfied. The Griffith locus is described by the equation relating the effective shear stress and shear strain related to the crack plane

$$
\gamma=\frac{\tau_{\text {eff }}}{G}+\frac{\pi^{3} K_{\text {IIc }}^{6}}{12 V G \tau_{\text {eff }}^{5}}
$$

where $V$ is the sample volume and $G$ is the shear modulus.

The tip of the Griffith locus corresponds to the minimum strain $\gamma_{e}$

$$
\gamma_{e}=6 / 5 \tau_{e} G^{-1}, \tau_{e}=K_{I I c} \sqrt{\pi}(12 / 5 V)^{-1 / 6}
$$

This point correspond to the crack size which is of the order of the sample size

$$
r_{e} \approx 0.335 V^{1 / 3}
$$

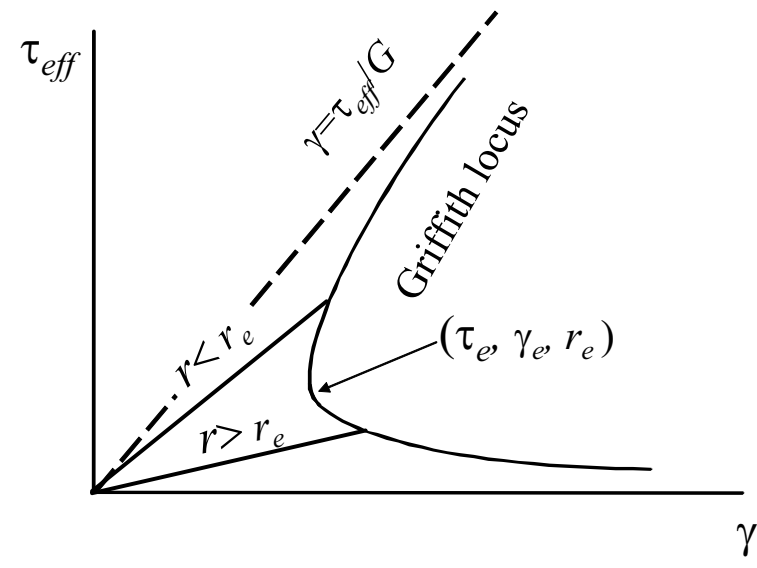

FIG. 10 Griffith locus in coordinates $\left(\gamma, \tau_{\text {eff }}\right)$

Subsequently, the post-peak behaviour depends upon the size $r$ of the crack at which criterion (4) is satisfied, Figure 10: only if the crack radius is already quite large, $r>r_{e}$, the postpeak branch will have negative slope, which corresponds to the situation shown in Figure 1, otherwise, if $r<r_{e}$, the postpeak branch will have positive modulus, which corresponds to the situation shown in Figure 2.

If one excludes the possibility of a large pre-existing crack in the sample (such a sample would likely be broken on the stage of extraction or machining) the situation of $r>r_{e}$ is only achievable when there exist a considerable phase of stable crack growth before the peak load is reached. If the crack growth is governed by equation (4) the only parameter that can ensure the stable crack growth is the increase in the effective fracture toughness $K_{I I C}$ as the crack size $r$ increases.

A possible mechanism that hampers growth of large cracks such that the fracture toughness increases with the shear crack size is its arrest on tensile microcracks intersecting its path, Figure 11a. These microcracks can be formed in compressive loading by local stress concentrators (e.g. wing cracks) or by spatial stress fluctuations (see Dyskin, 1999). These cracks can be small as shown in Figure 11a or large as shown in the photograph on Figure 1. 
A tensile microcrack intersecting the crack path causes its offset, Figure 11b (Galybin and Dyskin, 2004). This offset increases the effective fracture toughness.

Now it is clear that the particular form of the post-peak behaviour depends upon the concentration of tensile microcracks. If the concentration is low, the probability of intersecting the path of the dilating shear crack is low. Therefore the fracture toughness will not increase sufficiently to prevent the unstable crack growth from the very beginning and hence the post-peak branch of the Griffith locus will start at a branch with positive slope producing the situation shown in Figure 2. Only when the concentration of the tensile microcrack is sufficiently large the frequent intersections will make the fracture toughness sufficiently increase to ensure the shear crack enlargement in a stable mode to a size exceeding $r_{e}$ and thus activating the Griffith locus at a negative slope.

Concentration of the tensile microcracks is strongly affected by both lateral pressure and the loading rate. Since these microcracks are primarily oriented vertically, the lateral pressure reduces their concentration by reducing the number and size of the microcracks by suppressing their growth. The concentration of the tensile microcracks can also be reduced by the increase in strain rate because at high loading rated there is not enough time for the microcracks to develop. Subsequently, the increase in the lateral pressure or the loading rate reduces the microcrack concentration and thus removes the stabiliser of the shear crack growth. This leads to positive slope of the post-peak branch which manifest itself as violent failure, associated with embrittlement.

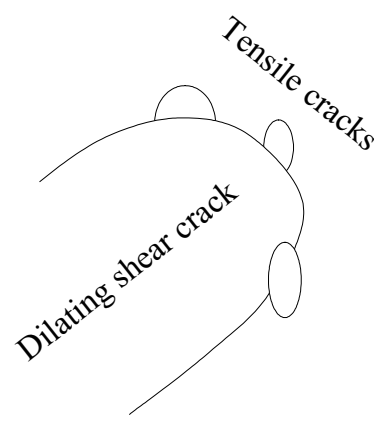

(a)

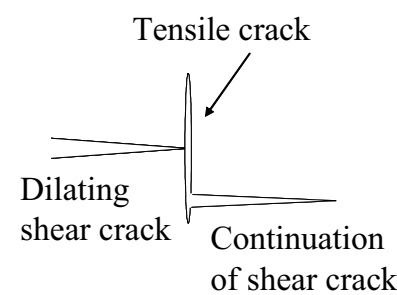

(b)
FIG. 11 A mechanism of size-dependent effective fracture toughness: (a) dilating shear crack arrested by tensile microcracks; (b) offset of the crack path after passing through a tensile microcrack as a mechanism of fracture toughness increase

\section{CONCLUSIONS}

An important phenomenon that can control the stability of rockmass and remote rockbursts is the anomalous rock embrittlement induced by confining pressure or dynamic impact when the post-peak branch of the loading curve becomes steeper as confining pressure or loading rate increase within a certain critical range of confining pressures or strain rates.

A possible mechanism of the embrittlement is the suppression of the accumulation of wing cracks because either the confining pressure hampers their growth or they simply do not have time to grow at high loading rates. In the absence of sufficient amounts of wing cracks the probability that they cross the path of the shear fracture is low and hence the unstable phase of the shear fracture growth can start at smaller lengths, producing, in accordance with the Griffith locus steep post-peak branch. As a result the failure localises along a single plane, subsequently the failure process is characterised by relatively low energy consumption resulting in a stiff post-peak branch. Outside the critical range of confining pressures or loading rates the failure pattern is more dispersed, the process is more power-consuming, which softens the post-peak branch.

In rockmass the embrittlement can be responsible for generation of unstable shear fractures at a distance from the excavation (where the confining pressures are high) causing remote rock burst. The phenomenon of embrittlement caused by confining pressure (minor stress) in rockmass can only take place below a certain depth where the minor stresses are within the critical stress range.

\section{ACKNOWLEDGMENT}

The authors acknowledge the financial support through a 2004 UWA Research Grant.

\section{REFERENCES}

Berry, J.P. (1960) Some kinetic considerations of the Griffith criterion for fracture. Parts I, II. J. Mech. Phys. Solids, 8, pp. 194-216.

Cook, N.G.W. (1965) The failure of rock. Int. J. Rock Mech. Min. Sci. \& Geomech. Abstr., 2, pp. 389-403.

Dyskin, A.V. (1999) On the role of stress fluctuations in brittle fracture. Intern. J. Fracture, 100, pp. 29-53.

Dyskin, A.V. and Galybin, A.N. (2001) Solutions for dilating shear cracks in elastic plane. Int J. Fracture, 109, pp. 325-344.

Dyskin, A.V., Germanovich, L.N. and Ustinov, K.B. (1994) Post-peak softening of brittle geomaterials in tension. In: Computer Methods and Advances in Geomechanics. Proc. Eighth Int. Conf. of the Association for Computer Methods and Advances in Geomechanics, IACMAG, 1, pp. 567-573.

Galybin, A.N. and Dyskin, A.V. (2004) Simulation of crack trajectories in materials with weak interfaces. Proc. Intern. Conference on Structural Integrity and Fracture (SIF2004) (in print).

Kemeny, J.M. and Cook, N.G.W. (1986) Effective moduli, non-linear deformation and strength of a cracked elastic solid. Int. J. Rock Mech. Min. Sci. \& Geomech. Abstr. 23, No. 2, pp. 107-118.

Ortlepp, W.D. (1997) Rock fracture and rockburst. The South African Institute of Mining and Metallurgy. Johannesburg, 98 pages.

Santarelli, F.J. and Brown, E.T. (1989) Failure of three sedimentary rocks in triaxial and hollow cylinder compression test. Int. J. Rock Mech. Min. Sci. \& Geomech. Abstr. 26, No. 5, pp. 401-413.

Stavrogin, A.N. and Tarasov, B.G. (2001) Experimental physics and rock mechanics. Balkema, 356 pages. 


\section{APPENDIX}

\section{Stiff Triaxial Static-Dynamic Testing Machine}

The experiments referred to in the paper (Figures 1, 2, 8) were conducted using a special loading machine recently built and commissioned at the UWA (ARC RIEF Grant 2000). The general view of the machine is shown in Figure 12. The machine provides a wide range of testing conditions including a high variation in confining pressure $(0-200 \mathrm{MPa})$ and strain rates $\left(10^{-7}-10^{+2} \mathrm{~s}^{-1}\right)$ as well as different kinds of cyclic loading. High stiffness and modern servo-controlling allow studying the rock behaviour in the post-peak region. One of the features of the machine is that the dynamic loading can be applied at any stage of the preliminary static loading.

In addition the machine contains precise flow measuring systems, in order to measure open porosity, rock permeability, and to investigate the effect of fracturing on the permeability development.

The machine provides servo-controlling of strain or stress rate, confining and pore pressure supply. Specimen sizes for the pressure cell are $36-38 \mathrm{~mm}$ in diameter and $76 \mathrm{~mm}$ in length. Under uniaxial compression the specimen sizes can be up to $100 \mathrm{~mm}$ in diameter and $200 \mathrm{~mm}$ in length.

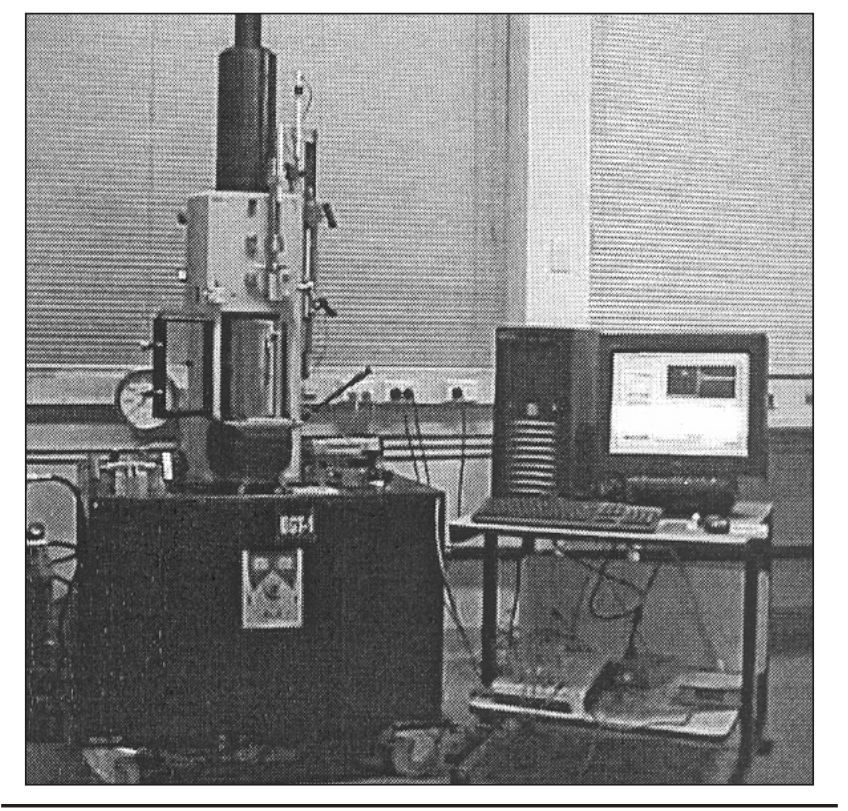

FIG. 12 General view of the rock testing machine 